\title{
Study on Prevalence of Small Ruminant Cysticercus Tenuicollis and its Monetary Loss at Bishoftu Elfora Export Abattoir, Oromia, Ethiopia
}

\author{
Yalelet Admasu ${ }^{2}$, Tekalign Tadesse ${ }^{1 *}$ and Zenebe Reta ${ }^{1}$ \\ ${ }^{1}$ Bedele College of Agriculture and forestry, Mettu University, Ethiopia \\ ${ }^{2}$ College of Veterinary Medicine, Samara University, Ethiopia
}

Submission: November 26, 2018; Published: January 22, 2019

*Corresponding author: Tekalign Tadesse, Mettu University, Bedele College of Agriculture and forestry, Ethiopia

\begin{abstract}
A cross-sectional study was conducted on Cysticercus tenuicollis in sheep and goats slaughtered at Bishoftu, Elfora export abattoir from November 2017 to April 2018 to determine the prevalence, organ preference and associated risk factors and to estimate direct economic losses attributed to the condemned organs from sheep and goats slaughtered in the abattoir. The statistical analysis was performed using SPSS program. The overall prevalence of $C$. tenuicollis from 500 shoats was found $323(64.6 \%)$ examined by post-mortem examination. During the study, a total of 268 goats and 232 sheep visceral organs were inspected. Of this C. tenuicollis was found in Caprine 60 (22.4\%) than in sheep 42 (18.1\%). The age wise prevalence $C$. tenuicollis showed that the prevalence was higher in young sheep (41.0\%) than adult sheep (20.8\%). Although organ wise infection rates of both sheep and goat were (19.4\%) and (20.5\%) (Mesentery), (19.8\%) and (18.3\%) (Peritoneum), (22.4\%) and (18.1\%) (Liver), and (18.3\%) and (17.2\%) (Omentum) and (18.3\%) and (21.6\%) (Carcass) with no significant statistical difference. The overall percentage of C. tenuicollis was higher in young sheep $(41.0 \%)$ than in adult sheep $(20.8 \%)$ with significant statistical difference ( $<<0.05)$. Small Ruminant Cysticercus tenuicollis is an important disease that causes great economic losses due to organ condemnation in the study area. Improvement of awareness of the communities about the economic importance of the parasite and hence reducing the incidence and economic loss incurred by the disease via control program that involves due attention on veterinary activities.
\end{abstract}

Keywords: Abattoir; C. tenuicollis; Monetary Loss; Prevalence; Small ruminant

Abbreviations: C. tenuicollis: Cysticercus tenuicollis; ETB: Ethiopian Birr; GDP: Growth Domestic Product; MASL: Mean Above Sea Level; SPSS: Scientific Program Social Science

\section{Introduction}

Ethiopia is a resourceful country endowed with largest livestock resource in African continent with about 53.99 million cattle, 25.5 million sheep and 24.06 million goats, 1.91 million horses, 6.75 million donkeys, 0.35 million mules, 0.92 million camels, 50.38 million poultry and 5.21 million bee hives [1] Livestock production is an important integral component of the Ethiopian agricultural production system and plays an imperative role in the development of the country's economy and for the food and nutritional security. The subsector contributes about $16.5 \%$ of the national Gross Domestic Product (GDP) and 35.6\% of the agricultural GDP [2]. Nowadays, parasitic diseases are significant causes of morbidity and mortality in humans as well as in animals [3] and are mostly found in warm tropical and sub-tropical regions of the world [4]. Many parasitic diseases are prevalent in Ethiopia, which are responsible for the low productivity of livestock besides contributing to reduced meat production due to carcass or organ condemnation [5]. In Ethiopia, parasitic diseases including C. tenuicollis in small ruminants were implicated as cause of organ condemnation in Abattoir enterprise leading to significant economic loss [6].

Cysticercus tenuicollis is the larval stage of Taenia hydatigena, which is a tapeworm of dogs, cats and wild canids [7] The intermediate hosts for the mature metacestode, $C$. tenuicollis, are sheep, goats, cattle, dromedaries, antelope, rarely pigs and reported in deer and horse monkey [8]. Metacestode stage are frequently found attached to the omentum, mesentery and to the serosa surface of abdominal organs, especially liver [7] and more frequently in the Omentum of goats and sheep [9]. Adult worms have been reported to be found in the small intestines of dogs, cats, mice and wild carnivores, like the Tinea hydatigena eggs with their faeces. Herbivores become infested with the eggs because of having feed on contaminated pastures. Possible intermediate hosts for $C$. Tenuicollis are squirrels, cattle, sheep, goats and other wild ruminants and swine. After ingestion, the egg's shell is digested and to Oncospheres become free to migrate through the intestinal walls, reaching the liver through the hepatic portal 
system. The Oncospheres may remain in the liver or migrate to the Omentum, mesenteries and the Serosal surface of the peritoneal cavity. However, unusual locations like the lungs, the kidneys and the brain, have also been reported [7].

Even though various investigations have been conducted to determine the prevalence of parasitic diseases resulting in organ condemnation in Ethiopia and most of the survey paid little attention to the study of $C$. tenuicollis prevalence only. Therefore, the objectives of the abattoir survey were to determine the prevalence of $C$. tenuicollis in sheep and goats slaughtered at Bishoftu Elfora Export abattoir, to find out the distribution of C. tenuicollis in visceral organs of sheep and goats and to assess the relationship between some risk factors and prevalence of $C$. tenuicollis in sheep and goats. Therefore, the objectives of this study were;

a. To determine the prevalence, and associated risk factors of $C$. tenuicollis.

b. To assess cyst distribution, Organ preference and Monetary Loss of the parasite in the study area.

\section{Materials and Methods}

\section{Study Area}

The study was conducted from November to April 2018 at Elfora Export abattoir in Bishoftu which is located at $90{ }^{\circ} \mathrm{N}$ and $40^{\circ} \mathrm{E}$ with an altitude of 1880 m.a.s.l in the central highlands of Ethiopia, $47 \mathrm{kms}$ southeast of Addis Ababa. It has annual rainfall of $1151.6 \mathrm{~mm}$ of which $84 \%$ falls during the long rainy season that extends from June to September and the remaining during the short rainy season that extends from March to May. The mean annual minimum and maximum temperatures is $8.50 \mathrm{C}$ and $30.70 \mathrm{C}$, respectively and the mean humidity is $61.3 \%$ [10].

\section{Study population and Study Design}

The study animals constituted of local breeds of small ruminants destined for slaughter were all males originated from different parts of the country. The animals were purchased from farmers on weight basis and the husbandry practice for these animals was mainly grazing. The study population was grouped into two age categories; based on dentition, for those which have not erupted permanent incisor teeth, are classified as young, while those with pair or more permanent incisor teeth erupted were classified as adult [11]. A cross-sectional study was conducted on 232 sheep and 268 goats at Elfora meat Export abattoir in Bishoftu from November 2017 to April 2018 by collecting data on events associated with $C$. tenuicollis on sheep and goats.

\section{Sampling Method and Sample size determination}

A systematic random sampling procedure was conducted to select individual animals for sampling in the abattoir and the study animals were randomly selected, recorded, mark and followed up through the completely slaughtering process. The male sheep and goats were grouped in to different categories of age. A systematic random sampling method employed by considering $50 \%$ expected prevalence and $95 \%$ confidence level with a $5 \%$ desired absolute precision and sample size was determined by the formula given by [12]. Even though the required sample size was 384, additional 116 samples were included to increase the precision so that 500 animals were included in the study.

$$
n=1.962 * \frac{P_{\exp }}{d^{2}}\left(1-P_{\exp }\right)
$$

Where, $n=$ required sample size

$\mathrm{P}_{\text {exp }}=$ expected prevalence

$\mathrm{d}=$ desired absolute precision (usually 0.05 )

\section{Sample Collection Method}

Pre-slaughter examinations were conducted in the lairage in order to determine the species age, body condition and origin of animals. Identification number was given for each animal to examine after evisceration. During ante-mortem examination animals were clinically examined for any sign of illness while standing and moving. During post mortem examination, visceral organs were thoroughly inspected by applying the routine meat inspection procedure (visualization, palpation and systemic incisions) for the presence of parasites and other abnormalities, paying attention to the visceral organs and tissues in abdominal, thoracic and pelvic cavities.

\section{Assessment of Financial Loss}

An attempt was made in order to estimate economic significance $C$. tenuicollis in small ruminant due to the cost of condemned liver. To calculate the economic loss, the following parameters were taken into consideration: The market demand, mean market price, the rejection rates of liver and annual slaughter capacity of the abattoirs. The economic loss due to liver condemnation was estimated by the formula set by [13] as follows:

$$
E L=\operatorname{Srx} * \operatorname{Coy}^{*} \operatorname{Roz}
$$

Where

$\mathrm{EL}=$ Annual economic loss estimated due to liver condemnation from international market.

Srx = Annual sheep/goats slaughter rate of the abattoir

Coy $=$ Average cost of each sheep or goat's liver.

\section{Data Management and Analysis}

The data was checked, coded and entered in to Microsoft excel work sheet and was analyzed using IBM SPSS software version 20. Descriptive statistics like percentage was used to express prevalence while chi-square $\left(\chi^{2}\right)$ test was used to compare the association of $C$. tenuicollis with different risk factors. In all the cases, 95\% confidence level and 0.05 absolute precision errors were considered. A p-value $\leq 0.05$ will be considered statistically significant.

\section{Result}

Out of 500 small ruminants examined by post-mortem examination $323(64.6 \%)$ of them were positive for $C$. tenuicollis. the prevalence of $C$. tenuicollis was relatively higher in Caprine $60(22.4 \%)$ than in sheep $42(18.1 \%)$ and there was no statisti- 


\section{Journal of Dairy \& Veterinary Sciences}

cally significant difference $(\mathrm{p}=0.236)$ in liver. The prevalence of C. tenuicollis was higher in 6-12 months both Caprine and sheep $45(22 \%)$ than in the 1 -2years $39(20.4 \%)$ and greater than two years $18(17.3 \%)$, Caprine and sheep without a statistically significant difference of $(\mathrm{p}=0.632)$. From 268 goats and 232 sheep brought from Somali and Borena 35(18.9\%) and 67(21.3\%) both Caprine and Sheep were positive respectively. In general, in this study the prevalence of $C$. tenuicollis was higher in goats and sheep originated from Borena parts of the country than Somali. There was no statistically significant difference between these two ori- gins of animals ( $\mathrm{p}$ value $=0.817 \%$ ). There was no significant difference revealed between body condition scores about cyst detection $(\mathrm{p}>0.05)$ in the organ of liver. In intestine the prevalence was $45(19.4 \%)$ in Ovine and Caprine 55(20.5\%) and in Pertonium $43(18.5 \%)$ in Ovine and Caprine 53(19.8\%), in Omentem the prevalence was $40(17.2 \%)$ in Ovine and Caprine and in carcass the prevalence was 50(21.6\%) in Ovine and in Caprine 49(18.3\%). in all organs the age, origin, body conditions were not a statistically significant difference ( $\mathrm{p}>0.05)$. The overall prevalence of organ condemnation was found to be $486 / 4000$ (12.15\%) (Table 1).

Table 1: Summary of liver condemnation.

\begin{tabular}{|c|c|c|c|c|c|}
\hline \multicolumn{2}{|c|}{ Variables } & Liver Examined & Liver Condemned (\%) & $\mathrm{X}^{2}$ & P value \\
\hline \multirow{2}{*}{ Spices } & Ovine & 232 & $42(18.1 \%)$ & \multirow{2}{*}{1.406} & \multirow{2}{*}{0.236} \\
\hline & Caprine & 268 & $60(22.4 \%)$ & & \\
\hline \multirow{3}{*}{ Age } & 6-12 months & 205 & $45(22 \%)$ & \multirow{3}{*}{0.916} & \multirow{3}{*}{0.632} \\
\hline & $1-2 \mathrm{yr}$ & 191 & $39(20.4 \%)$ & & \\
\hline & $>2 \mathrm{yr}$ & 104 & $18(17.3)$ & & \\
\hline \multirow{2}{*}{ Origin } & Somali & 185 & $35(18.9 \%)$ & \multirow{2}{*}{0.397} & \multirow{2}{*}{0.529} \\
\hline & Borena & 315 & $67(21.3 \%)$ & & \\
\hline \multirow{4}{*}{ Body condition } & Poor & s55 & $14(25.5 \%)$ & \multirow{3}{*}{1.354} & \multirow{3}{*}{0.508} \\
\hline & Medium & 380 & $77(20.3 \%)$ & & \\
\hline & Good & 65 & $11(16.9 \%)$ & & \\
\hline & Overall & 500 & $102(20.4 \%)$ & & \\
\hline \multicolumn{6}{|c|}{ Annual Liver cost of goat $=0.224$ condemnation rate $* 65 \mathrm{ETB}^{*} 100000$ goat $=1,456,000$ ETB } \\
\hline \multicolumn{6}{|c|}{ Annual Liver cost of sheep $=0.18 * 70$ ETB $* 30,000=380,100$ ETB } \\
\hline
\end{tabular}

Of the total 500 animals inspected for intestine, 100 (20\%) animals had condemned intestine due to $C$. tenuicollis. The intestine condemnation rate was $19.4 \%$ and $20.5 \%$ in Ovine and Caprine respectively. But there was no statistically significant $(\mathrm{P}>0.05)$ difference between spices, age, origin of animal and body condition groups (Table 2). Overall peritoneum organ condemnation 96(19.2\%) was found higher on animals who brought from Borana $62(19.7 \%)$, Caprine 53(19.8\%), the age of animals above the age of two years $24(23.1 \%)$ and poor body condition 14 (25.5\%) even though there was no statically significance difference among variables (Table 3). Exposure to multiple organ condemnation is found higher on Animals originated from Borane have high number of organ condemnation pre animal, Caprine species have high count of organ condemnation per animal, Generally, number of organ condemnation higher on the 6-12-month age, however one organ condemnation is high on the age category of 1-2 year and also prevalence of organ condemnation is high on the medium body conditioned animals.

Table 2: Summary of intestinal condemnation.

\begin{tabular}{|c|c|c|c|c|c|}
\hline \multicolumn{2}{|c|}{ Variables } & Intestine Examined & Intestine Condemned (\%) & $\mathbf{X}^{2}$ & $P$ value \\
\hline \multirow{2}{*}{ Spices } & Ovine & 232 & $45(19.4 \%)$ & \multirow{2}{*}{0.099} & \multirow{2}{*}{0.754} \\
\hline & Caprine & 268 & $55(20.5 \%)$ & & \\
\hline \multirow{3}{*}{ Age } & 6-12 mo & 205 & $41(20 \%)$ & \multirow{3}{*}{1.34} & \multirow{3}{*}{0.512} \\
\hline & $1-2 \mathrm{yr}$ & 191 & $42(22 \%)$ & & \\
\hline & $>2 \mathrm{yr}$ & 104 & $17(16.3 \%)$ & & \\
\hline \multirow{2}{*}{ Origin } & Somali & 185 & $38(20.5 \%)$ & \multirow{2}{*}{0.054} & \multirow{2}{*}{0.817} \\
\hline & Borena & 315 & $62(19.7 \%)$ & & \\
\hline \multirow{4}{*}{ Body condition } & Poor & 55 & $11(20 \%)$ & \multirow{3}{*}{0.113} & \multirow{3}{*}{0.945} \\
\hline & Medium & 380 & $75(19.7 \%)$ & & \\
\hline & Good & 65 & $14(21.5 \%)$ & & \\
\hline & Overall & 500 & $100(20 \%)$ & & \\
\hline
\end{tabular}




\section{Journal of Dairy \& Veterinary Sciences}

Table 3: Summary of Peritoneum condemnation.

\begin{tabular}{|c|c|c|c|c|c|}
\hline \multicolumn{2}{|c|}{ Variables } & Peritoneum Examined & Peritoneum Condemned (\%) & $\mathbf{X}^{2}$ & $P$ value \\
\hline \multirow{2}{*}{ Spices } & Ovine & 232 & $43(18.5 \%)$ & \multirow{2}{*}{0.124} & \multirow{2}{*}{0.725} \\
\hline & Caprine & 268 & $53(19.8 \%)$ & & \\
\hline \multirow{3}{*}{ Age } & 6-12 mo & 205 & $36(17.6 \%)$ & \multirow{3}{*}{1.378} & \multirow{3}{*}{0.502} \\
\hline & $1-2 \mathrm{yr}$ & 191 & $36(18.8 \%)$ & & \\
\hline & $>2 \mathrm{yr}$ & 104 & $24(23.1 \%)$ & & \\
\hline \multirow{2}{*}{ Origin } & Somali & 185 & $34(18.4 \%)$ & \multirow{2}{*}{0.128} & \multirow{2}{*}{0.721} \\
\hline & Borena & 315 & $62(19.7 \%)$ & & \\
\hline \multirow{4}{*}{ Body condition } & Poor & 55 & $14(25.5 \%)$ & \multirow{4}{*}{1.558} & \multirow{4}{*}{0.459} \\
\hline & Medium & 380 & $70(18.4 \%)$ & & \\
\hline & Good & 65 & $12(18.5 \%)$ & & \\
\hline & Overall & 500 & $96(19.2 \%)$ & & \\
\hline
\end{tabular}

\section{Discussion}

The present investigation showed that Out of 232 sheep and 368 goats examined in liver, intestine, Pertonium, Omentem and Carcass 102(20.4\%), 100(20\%), 96(16.2\%), 89(17.8\%), 99(19.8) respectively were found to be positive for $C$. tenuicollis. This finding was in line with the finding of $[14,15](22.8 \%$ and $26.4 \%)$ from Turkey and Nigeria respectively and [16] (24.6\%) in Dire Dawa municipal abattoir and Tadessena). However, it was relatively lower when compared to the finding of [17] who had reported to be $46.1 \%$ in Dessie and [18] (37.1\%,) in Addis Ababa abattoir and relatively higher when compared to the finding of $15.7 \%$ [19] and $4.21 \%$ [20] in Iran. This variation in the prevalence mainly accounted to the grazing behavior and management system prevailing in the local areas [14] (Table 4).

Table 4: Summary of Omentem condemnation.

\begin{tabular}{|c|c|c|c|c|c|}
\hline \multicolumn{2}{|c|}{ Variables } & Omente Mexamined & Omentem Condemned (\%) & $\mathbf{X}^{2}$ & P value \\
\hline \multirow{2}{*}{ Spices } & Ovine & 232 & $40(17.2 \%)$ & \multirow{2}{*}{0.92} & \multirow{2}{*}{0.761} \\
\hline & Caprine & 268 & $49(18.3 \%)$ & & \\
\hline \multirow{3}{*}{ Age } & 6-12 mo & 205 & $37(18 \%)$ & \multirow{3}{*}{0.06} & \multirow{3}{*}{0.97} \\
\hline & $1-2 \mathrm{yr}$ & 191 & $33(17.3 \%)$ & & \\
\hline & $>2 \mathrm{yr}$ & 104 & $19(18.3 \%)$ & & \\
\hline \multirow{2}{*}{ Origin } & Somali & 185 & $33(17.8 \%)$ & \multirow{2}{*}{0} & \multirow{2}{*}{0.986} \\
\hline & Borena & 315 & $56(17.8 \%)$ & & \\
\hline \multirow{4}{*}{ Body condition } & Poor & 55 & $9(16.4 \%)$ & \multirow{3}{*}{0.437} & \multirow{3}{*}{0.804} \\
\hline & Medium & 380 & $70(18.4)$ & & \\
\hline & Good & 65 & $10(15.4 \%)$ & & \\
\hline & Overall & 500 & $89(17.8 \%)$ & & \\
\hline
\end{tabular}

Table 5: Summary of carcass condemned.

\begin{tabular}{|c|c|c|c|c|c|}
\hline \multicolumn{2}{|c|}{ Variables } & Carcass Examined & Carcass Condemned (\%) & $\mathbf{X}^{2}$ & $P$ value \\
\hline \multirow{2}{*}{ Spices } & Ovine & 232 & $50(21.6 \%)$ & \multirow{2}{*}{0.836} & \multirow{2}{*}{0.36} \\
\hline & Caprine & 268 & $49(18.3 \%)$ & & \\
\hline \multirow{3}{*}{ Age } & 6-12 mo & 205 & $34(16.6 \%)$ & \multirow{3}{*}{2.668} & \multirow{3}{*}{0.263} \\
\hline & $1-2 \mathrm{yr}$ & 191 & $40(20.9 \%)$ & & \\
\hline & $>2 \mathrm{yr}$ & 104 & $25(24 \%)$ & & \\
\hline \multirow{2}{*}{ Origin } & Somali & 185 & $39(21.1 \%)$ & \multirow{2}{*}{0.303} & \multirow{2}{*}{0.582} \\
\hline & Borena & 315 & $60(19 \%)$ & & \\
\hline \multirow{3}{*}{ Body condition } & Poor & 55 & $11(20 \%)$ & \multirow{3}{*}{0.084} & \multirow{3}{*}{0.959} \\
\hline & Medium & 380 & $76(20 \%)$ & & \\
\hline & Good & 65 & $12(18.5 \%)$ & & \\
\hline
\end{tabular}




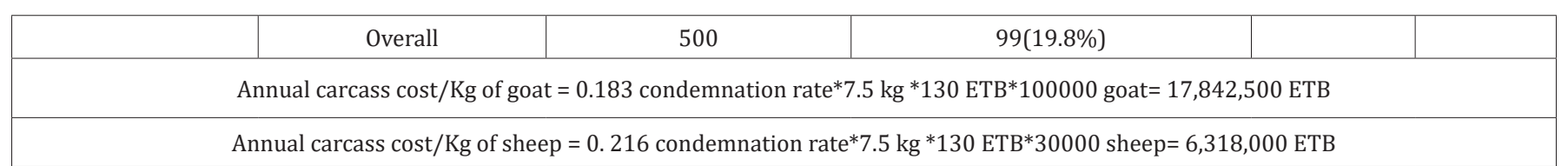

The prevalence of $C$. tenuicollis by species was higher in goats $(54.2 \%)$ as compared to sheep (35.4\%). This may be due to close contact between dogs and goats. According to [21], under condition of high infestation of $C$. tenuicollis most sheep develop protective immunity early in life and this immunity regulate the parasite population, whereas goat develops the immunity more slowly. Similar result was reported in a study done by [22], who has recorded prevalence of 17, 14, 12 and 15\% in Sheep, and 38, 30,32 and $35 \%$ in goats, respectively at Haramaya, Harar, Dire Data and Jijiga Abattoirs (Table 5).

The prevalence by age revealed that higher infestation rates was recorded in animals with the age of adults (above one year and two years age) $(40.7 \%$ in adult and the lowest prevalence was recorded in younger animals (6-month -1-year age) (32.6\%) (Table 6). This finding is in line with the finding in three export abattoirs. Although organ wise infestation rate of both sheep and goats were comparable $18.1 \%$ and $22.4 \%$ (liver). $18.5 \%$ and $19.8 \%$ (peritoneum), $19.4 \%$ and $20.5 \%$ (mesentery) and with the lost infestation $17.2 \%$ and $18.3 \%$ in (Omentum). These results disagree with results of Cystcerci in sheep (84.85\%) and goats (82.14\%) Omentum by [19]. The infestation rate of $C$. tenuicollis was higher in the omentum of adult goats $(67.4 \%)$ than the young ones $(57.9 \%)$. Therefore, regarding the infestation rate of $C$. tenuicollis; there was a statistically significant difference between young and adult goats and sheep.

Table 6: summary of number of organs condemned per single animal.

\begin{tabular}{|c|c|c|c|c|c|c|c|}
\hline \multicolumn{2}{|c|}{ Variables } & \multirow{2}{*}{$\begin{array}{c}\text { Non-condemned } \\
65(36.7 \%)\end{array}$} & \multirow{2}{*}{$\begin{array}{c}\text { Only one organ } \\
71(35.7 \%)\end{array}$} & \multirow{2}{*}{\begin{tabular}{|l} 
Two organs \\
$41(44.6 \%)$
\end{tabular}} & \multirow{2}{*}{$\begin{array}{c}\text { Three organs } \\
6(23.1 \%)\end{array}$} & \multirow{2}{*}{$\begin{array}{c}\text { Four organs } \\
2(33.3 \%)\end{array}$} & \multirow{4}{*}{$\begin{array}{c}\text { P Value } \\
0.33\end{array}$} \\
\hline \multirow{3}{*}{ Origin } & Somali & & & & & & \\
\hline & Borane & $112(63.3 \%)$ & $128(64.3 \%)$ & $51(55.4 \%)$ & $20(76.9 \%)$ & $4(66.7 \%)$ & \\
\hline & Overall & $177(35.4 \%)$ & 199(39.8\%) & $92(18.4 \%)$ & $26(5.2 \%)$ & $6(1.2 \%)$ & \\
\hline \multirow{3}{*}{ Species } & Ovine & $81(45.8 \%)$ & $95(47.7 \%)$ & $45(48.9)$ & $9(34.6 \%)$ & $2(33.3 \%)$ & \multirow{3}{*}{0.68} \\
\hline & Caprine & $96(54.2 \%)$ & $104(52.3 \%)$ & $47(51.1 \%)$ & $17(65.4 \%)$ & $4(66.7 \%)$ & \\
\hline & Overall & $177(35.4 \%)$ & $199(39.8 \%)$ & $92(18.4 \%)$ & $26(5.2 \%)$ & $6(1.2 \%)$ & \\
\hline \multirow{4}{*}{ Age } & 6-12 mo & $81(45.8 \%)$ & $72(36.2 \%)$ & $38(41.3 \%)$ & $11(42.3 \%)$ & $3(50 \%)$ & \multirow{4}{*}{0.58} \\
\hline & 1-2 year & $64(36.2 \%)$ & $81(40.7 \%)$ & $32(34.8 \%)$ & $11(42.3 \%)$ & $3(50 \%)$ & \\
\hline & above $2 \mathrm{y}$ & $32(18.1 \%)$ & $46(23.1 \%)$ & $22(23.9 \%)$ & $4(15.4 \%)$ & 0 & \\
\hline & Overall & $177(35.4 \%)$ & $199(39.8 \%)$ & $92(18.4 \%)$ & $26(5.2 \%)$ & $6(1.2 \%)$ & \\
\hline \multirow{4}{*}{$\begin{array}{l}\text { body condi- } \\
\text { tion }\end{array}$} & Poor & $16(9 \%)$ & $24(12.1 \%)$ & $11(12 \%)$ & $3(11.5 \%)$ & $1(16.7 \%)$ & \multirow{4}{*}{0.96} \\
\hline & Medium & 137(77.4\%) & $147(73.9 \%)$ & $72(78.3 \%)$ & $20(76.9 \%)$ & $4(66.7 \%)$ & \\
\hline & Good & $24(13.6 \%)$ & $28(14.1 \%)$ & $9(9.8 \%)$ & $3(11.5 \%)$ & $1(16.7 \%)$ & \\
\hline & Overall & $177(35.4 \%)$ & 199(39.8\%) & $92(18.4 \%)$ & $26(5.2 \%)$ & $6(1.2 \%)$ & \\
\hline
\end{tabular}

Body condition of sheep was the only risk factor in which the prevalence of $C$. tenuicollis poor body condition (11\%) was found most infected significantly varied. sheep with compared to medium (76\%) and good (13.8\%) body condition. among all other risk factors considered both in sheep and goats except the slight difference in figures of the prevalence statistically no significant variation observed. this finding is in line with the report of poor body condition (39.8\%) medium body condition (21.8\%) and good $(14.8 \%)$ body condition this finding is in line with Togerson $[9,14,21]$ from northern Jordan, turkey and central Ethiopia respectively. when all studied animals considered together, still the prevalence significantly varied. with body condition. Small ruminant with poor body conditions were the most affected compared to the medium and good body conditions. When animals suffer from shortage or scarcity of nutrition and infected with gastrointestinal internal parasites their immunity compromised. Hence, possibly this can be accounted for the higher prevalence of the cyst in poor body condition animals.

Among the predilection sites observed during this study liver was found to be the predominant one, and it followed by Omentum and peritoneum. Samuel \& Zewde $[9,14]$ reported that Omentum is the predominant predilection sites for $C$. tenuicollis. During the study, from the total shoats slaughtered, parasite like C. tenuicollis was found to be the major causes that rendered liver rejection from international market. The spreading of infection 
is an indication of environmental contamination with the eggs of the adult dog tapeworms. C. tenuicollis is the most important and widely prevalent of the four metacestodes recording in small ruminants slaughtered in the study abattoir. Upto18.1\% of the slaughtered sheep and goats were found to be infected with the $C$. tenuicollis. The prevalence of $C$. tenuicollis by species was slightly higher in goats (39.5\%) as compared to sheep (36.2\%). however, this difference was not found statistically significant. similar results were reported in goats in Nigeria [15].

In the current study; overall annual economic losses due to a single organ condemnation (liver) from sheep and goats infested by C. tenuicollis was estimated to be: 1836100 ETB. This result is lower than the report of [23] who estimated an economic loss of $65,269.89$ SUA or 1,044317.79 ETB from condemned liver. The economic loss in the abattoir was relatively high because of its export standard in which any liver with single cyst or calcified liver with cyst was disposed from international market. Such loses are importance in Ethiopia, which has low economic output where sheep and goat production are the major livestock industries.

\section{Conclusion and Recommendation}

C. tenuicollis was the predominant metacestode causing organ disposal with consequent economic losses in the study of export abattoirs practicing the slaughter of sheep and goat and exporting meat of these animal products. High prevalence of $C$. tenuicollis was recorded in slaughtered sheep and goats. Some of the abattoirs can enhance the continuation of the life cycle between the intermediate host and final hosts without appropriate disposal of abattoir materials. Based on the results of the present study, the following recommendations are forwarded:

a. Proper attention should be paid to the safe and controlled elimination of all condemned abattoir materials and the sale of contaminated offal's and organs of sheep and goats and feeding of dogs should be stopped.

b. Awareness creation programs should be given for the butchers, abattoirs workers, meat sellers, and dog owners about the danger of the metacestodes for human and animal health.

c. Strategic application of chemotherapy with appropriate anthelmintic at appropriate time should be implemented.

A control program should be mounted on the number of stray dogs in the study area due to their involvement in the life cycle of the parasite.

\section{References}

1. Central Statistics Authority (2013) Ethiopia agricultural Statistical report on livestock and livestock characteristics. The Federal Democratic Republic of Ethiopia, Central Statistical Agency (CAS), private peasant holding. Statistical bulletin 570, Addis Ababa, Ethiopia.

2. Metaferia F, Cherenet T, Gelan A, Abnet F, Tesfay A, et al. (2011) Review to Improve Estimation of Livestock Contribution to the National GDP. Ministry of Finance and Economic Development and Ministry of Agriculture, Addis Ababa, Ethiopia.
3. Pal M (2007) Zoonoses. ( $2^{\text {nd }}$ edn), Satyam Publishers, Jaipur, India pp. $1-362$.

4. Hadush A, Pal M (2016) Ascariasis: Public health implications and its status in Ethiopia. Air and Water Borne Diseases 5: 124.

5. Nasr W, Pal M (2016) Prevalence, cysts viability, fertility and economic significance of bovine hydatidosis in an abattoir at Kombolcha, Ethiopia. Haryana Veterinarian 55: 17-22.

6. Yehualashet B, Aklilu K, Tsegaye A (2012) Prevalence and economic importance of liver parasites: Hydatid cyst, Fasciola species and cysticercus tenuicollis in sheep and goats slaughtered at Addis Ababa abattoir enterprise in Ethiopia. Journal of veterinary medicine and animal health, 5: 17 .

7. Taylor M, Coop R (2007) Veterinary Parasitology, ( $3^{\text {rd }}$ edn), Black Well Science Ltd, Iowa, and USA, pp. 210-211.

8. Tsubota K, Nakatsuji S, Matsumoto M, Fujihira S, Yoshizaw K, et al. (2009) Abdominal cysticercosis in a cynomolgus monkey, short communication. Vet Parasitol 161: 339341.

9. Samuel G, Zewde G (2010) Prevalence, risk factors, and distribution of $C$. tenuicollis in visceral organs of slaughtered sheep and goats in Central Ethiopia. Trop Anim Health Prod 42: 1049-1051.

10. NMSA, National Meteorology Service Agency (2003) Addis Ababa, Ethiopia

11. Alemu Y, Merkel R (2008) Sheep and goats' production and Handbook for Ethiopia, p. 2.

12. Thrusfield M (1995) Veterinary Epidemiology, ( $2^{\text {nd }}$ edn), University of Edinburgh, Blackwell science. pp. 180-188.

13. Ogunrinade A (1980) Economic importance of Fasciolosis in Nigeria. Trop Anim Hlth Prod 12: 155- 160.

14. Senlik B (2008) Influence of host breed, sex and age on the prevalence and intensity of $C$. tenuicollis in sheep. J anim vet Adv 7(5): 548-551.

15. Dada B, Belino E (1978) prevalence of hydatidosis and cysticercosis in slaughtered livestock in Nigeria. The veterinary record, 103: 311-312.

16. Endale M, Shihun, Jemere B, Desie S (2013) Sheep and goats Cysticercustenuicollis prevalence and associated risk factors. Afri J Agri Res 8: 3121-3125.

17. Yilikal M (1989) Hydatidosis in cattle, sheep, pigs; cysticercus tenuicollis in sheep around dessie and the efficacy hageniaabyssinica (kosso) on taeniahydatigena. Dvm thesis, AAU, Ethiopia, p. 11-18.

18. Tekleye B, Mukasa M, Kasali o (1988) Prevalence perspective and annotated bibliography. cab. International, pp. 285.

19. Radfar M, Tajalli S, Jalalzadeh M (2005) prevalence and morphological characterization of $C$. tenuicollis (taenia hydatigena) from sheep and goats in Iran. Vet Arh 75: 469-496.

20. Khanjari, A, Cheraghi S, Bokaie S, Fallah, B, Akhondzadeh M, et al. (2015) Prevalence of cysticercustenuicollis in slaughtered sheep and goats by season, sex, age and infected organ at Amol abattoir, mazandaran province. Iran, J comp clin Pathol 24: 149-152.

21. Torgerson P, Williams D and Abo-Shehada M, (1998) Modelling the Prevalence of Echinococcus and Taenia Species in Small Ruminants of Different Ages in Northern Jordan. Vet Parasitol 79: 35-51.

22. Sisay M, Uggla A, Waller P (2007) Prevalence and Seasonal Incidence of Nematode Parasites and Fluke Infestation of Sheep and Goat in Eastern Ethiopia. Trop Anim Health Prod 39: 521-531.

23. Wondimu A, Abera T, Hailu y (2011) A study on the prevalence, distribution and economic importance of cysticercus tenuicollis in visceral organs of small ruminants slaughtered at an abattoir in Ethiopia. Jvamh 3: 67-74. 
Your next submission with Juniper Publishers

will reach you the below assets

- Quality Editorial service

- Swift Peer Review

- Reprints availability

- E-prints Service

- Manuscript Podcast for convenient understanding

- Global attainment for your research

- Manuscript accessibility in different formats

( Pdf, E-pub, Full Text, Audio)

- Unceasing customer service

Track the below URL for one-step submission https://juniperpublishers.com/online-submission.php 